\title{
Semelhanças e considerações sobre o contrato de interinidad na Espanha e no Brasil
}

\author{
Similarities and considerations about the interim contract in Spain and Brazil
}

\author{
LEANDRO ANTONIO PAMPLONA ${ }^{a}$
}

\begin{abstract}
RESUMO
O presente estudo tem o objetivo de apresentar as semelhanças entre o contrato de interinidad espanhol e o contrato de prazo determinado no Brasil.

Palavras-chave: Contrato temporário. Contrato por prazo determinado. Forma do contrato no Brasil e na Espanha.
\end{abstract}

\begin{abstract}
The present study intends to present the similarities between the interim contract in Brazil and Spain.

Keywords: Interim contract. Temporary contract. The contract format in Brazil and Spain.
\end{abstract}

\section{IDENTIFICANDO O CONTRATO DE} INTERINIDAD ESPANHOL COM SEU SEMELHANTE NO DIREITO BRASILEIRO

O primeiro passo, para que se possa encontrar qual o contrato de trabalho dentro do direito brasileiro que mais se assemelha ao contrato de interinidad espanhol, é preciso traduzir a palavra interinidad. A tradução literal da palavra para o português é interinidade, ou seja, qualidade do que é interino ${ }^{1}$. Por sua vez o interino remete a temporário, tanto na Língua Portuguesa quanto na Espanhola ${ }^{2}$.

Todavia, contrariando a lógica, o contrato de interinidad espanhol se assemelha muito mais ao contrato a prazo, ou por prazo determinado, do que ao contrato de trabalho temporário existente no ordenamento jurídico brasileiro, como a seguir ficará demonstrado.

O trabalho de interinidad na Espanha serve para substituir trabalhadores com direito à reserva do seu posto de trabalho ${ }^{3}$, ou seja, a empresa contrata outro empregado para entrar no lugar daquele que se ausenta temporariamente, permanecendo relação direta entre empregador e empregado. No Brasil, o trabalhador temporário serve para atender uma necessidade transitória de substituição de pessoal regular e permanente ou a acréscimo extraordinário de serviços ${ }^{4}$. Entra em cena uma empresa de trabalho temporário ou terceirizante.

Como se pode observar, o objetivo do contrato de interinidad espanhol e do contrato temporário brasileiro é muito parecido, todavia existe grande diferença na relação trabalhista, pois na realidade brasileira o vínculo do trabalhador temporário não é com a empresa que toma diretamente seus serviços, mas sim, com a empresa de trabalhos temporários, diferentemente da realidade espanhola, na qual o tomador contrata diretamente o prestador.

\subsection{Previsão legal}

Na Espanha o contrato de interinidad está regulamentado em diversos textos legislativos. No Estatuto dos Trabalhadores ele está previsto no artigo 15.1.c c $^{5}$ Além do Estatuto, encontra complementação

\footnotetext{
a Doutorando e Mestre em Direito pela PUCRS. Professor da Universidade de Santa Cruz do Sul. Professor convidado nos cursos de Pós-Graduação da FEVALE e IMED. Advogado sócio do escritório Bonetti, Krugen \& Pamplona Advogados. <pamplona@advogadors.com.br>.
} 
no R.D.LG. 1/95, art.15; disp. adicional 14쓸 R.D. 2720/98, R.D.L. 11/98, Lei 12/01, Lei 45/02, L.O. 1/04, Lei 43/06 e R.D.L. 20/12.

O Estatuto possui uma previsão geral dessa modalidade contratual enquanto as demais leis especificam em que hipóteses ele pode existir. Tome-se, por exemplo, o Real Decreto 2720/986 que acrescenta além da reserva do posto de trabalho em virtude de norma, convênio coletivo ou individual, a possibilidade de implementar essa modalidade contratual para cobrir temporariamente um posto de trabalho durante o processo de seleção ou promoção para sua cobertura definitiva.

Dessa forma, as leis esparsas têm o papel de definir em que situações o contrato temporário poderá existir.

Todavia, essa pluralidade de situações, previstas em diversas leis esparsas, trouxeram imensas dificuldades aos órgãos judiciários no sentido do alcance material do contrato temporário. Conforme ressalta Diego Megino Fernandez $^{7}$, citando julgado do Tribunal Superior de Justiça das Astúrias (AS 2004, 2192), em alguns casos se entendeu que não haveria justificativa para se aceitar o contrato temporário, tal como força maior, causas econômicas ou tecnológicas, enquanto em outros havia forte dúvida, como, por exemplo, casos especiais para cuidado dos filhos e exercício de funções sindicais.

Através desse julgado é possível entender a dificuldade que a própria jurisprudência espanhola possui em determinar as situações que admitirão o contrato temporário.

Diferente da miscelânea de leis que desenvolvem e definem o contrato de interinidad na Espanha, no Brasil, o contrato por prazo determinado está previsto na CLT no art. $443, \S 1^{\circ}$, enquanto o contrato temporário está regulado fora da CLT, mais especificamente na Lei no ${ }^{\circ} .019 / 74$ e no Decreto 73.841/74.

\subsection{Conceito do contrato de interinidad, temporário e por prazo determinado}

$\mathrm{Na}$ Espanha, o contrato temporário, de acordo com a definição constante na página do Ministério do emprego e da previdência social do Governo, tiene como objetivo sustituir a un trabajador con derecho a reserva de puesto de trabajo, en virtud de norma, convenio colectivo o acuerdo individual, o para cubrir temporalmente un puesto de trabajo durante el proceso de selección o promoción, para su cobertura definitiva, así como para sustituir a trabajadores en formación por trabajadores beneficiarios de prestaciones por desempleo ${ }^{8}$.

No Brasil o trabalho temporário está definido no art. $2^{\circ}$ da Lei $n^{\circ}$ 6.019/74, como "aquele prestado por pessoa física a uma empresa, para atender à necessidade transitória de substituição de seu pessoal regular e permanente ou a acréscimo extraordinário de serviços". Entretanto, de acordo com Amauri Mascaro do Nascimento 9 essa definição deve ser complementada com o art. $4^{\mathrm{O}}$ da mesma Lei que compreende como empresa de trabalho temporário "a pessoa física ou jurídica urbana, cuja atividade consiste em colocar à disposição de outras empresas, temporariamente, trabalhadores, devidamente qualificados, por elas remunerados e assistidos".

O trabalhador temporário, de acordo com o art. 16 do Decreto $73.841 / 74$, é a pessoa física contratada por empresa de trabalho temporário, para prestação de serviço destinado a atender à necessidade transitória de substituição de pessoal regular e permanente ou a acréscimo extraordinário de tarefas de outras empresas.

Logo, o trabalhador temporário é aquele que está juridicamente vinculado a uma empresa de trabalho temporário, com quem mantém contrato de trabalho e recebe suas parcelas contratuais, mas presta serviço a outra empresa, que possui uma necessidade transitória de substituição de pessoal ou acréscimo extraordinário dos serviços ${ }^{10}$.

No Brasil, a regra é do contrato por prazo indeterminado ${ }^{11}$. Inclusive, quando as partes não convencionam previamente o fim do contrato, ele será presumido como contrato por prazo indeterminado. De acordo com o art. 443 da CLT, os contratos de emprego em que as partes fixam uma data final são denominados contratos a prazo.

O $\S 1^{\circ}$ do art. 443 da CLT deixa claro que é um contrato cuja vigência depende de termo prefixado ou da execução de serviços especificados ou ainda da realização de certo acontecimento suscetível de previsão aproximada.

\subsection{Distinção entre o contrato por prazo determinado e contrato temporário no direito brasileiro}

Conforme já foi visto, o contrato de iterinidad espanhol funciona para substituir trabalhadores com direito à reserva do seu posto de trabalho. O empregador contratará outra pessoa para ocupar o lugar daquela afastada temporariamente. Com o regresso do afastado, extinto estará o contrato com temporário.

O trabalhador temporário no Brasil, também presta seu serviço de forma temporária e tem como objetivo preencher uma necessidade transitória do empregador. Contudo, se afasta do modelo espanhol na medida em que é necessária uma empresa de trabalho temporário, portanto específica, para oferecer esse tipo de empregado. Não há possibilidade do tomador contratar diretamente esse tipo de empregado, sob 
pena, de desconfiguração dessa modalidade contratual.

O empregado, na verdade, é contratado por empresa prestadora de mão de obra, a fim de prestar seus serviços a um tomador, sem que haja vínculo de emprego com a empresa tomadora ou cliente $^{12}$. O trabalhador temporário é empregado de uma empresa específica de trabalhadores temporários, embora preste serviços nas dependências da empresa tomadora, por determinação daquela, enquanto o trabalhador de contrato por prazo determinado, presta serviço por um tempo estabelecido na própria empresa tomadora ${ }^{13}$.

Em verdade cria-se uma relação triangular entre o trabalhador temporário, a empresa de trabalho temporário (empregadora direta) e o tomador ou cliente, que é quem contrata os serviços. O vínculo jurídico estabelece-se com a empresa de trabalho temporário ${ }^{14}$ e não com a tomadora, muito embora tenha se reconhecido que a administração pública, através de edital, possa contratar temporariamente para preenchimento de vaga de empregado afastado ${ }^{15}$.

A empresa tomadora não contrata diretamente o empregado temporário, e é isso que torna o contrato de interinidad mais parecido com o contrato a prazo.

De acordo com a Lei 6019/74 existem duas hipóteses que autorizam o contrato temporário, são elas: atendimento a necessidades transitórias de substituição de pessoal regular e permanente da empresa tomadora; e a necessidade resultante de acréscimo extraordinário de serviços da empresa tomadora.

A seu turno, o contrato por prazo determinado possui três hipóteses de pactuação previsto na CLT (art.443, § $2^{\circ}$ ). A primeira cuja natureza ou transitoriedade justifique a predeterminação do prazo; a segunda as atividades empresarias transitórias; e a terceira o contrato de experiência. Ainda poderia identificar uma quarta no caso do atleta de futebol, e uma quinta a partir da Lei 9.601/98 ${ }^{16}$.

A determinação do tempo pode ou não estar vinculada ao resultado. Existem contratos com data final estipulada e contratos que finalizarão apenas com o alcance do resultado ${ }^{17}$.

\section{REQUISITOS PARA VALIDADE FORMAL DO CONTRATO DE INTERINIDAD E DO CONTRATO POR PRAZO DETERMINADO}

Os requisitos formais ${ }^{18}$ do contrato de interinidad decorrem da doutrina e da jurisprudência ${ }^{19}$, no direito espanhol. São eles:

1. Causa da substituição; motivo pelo qual o trabalhador foi substituído, saúde, licença maternidade, ou outras.
2. A identificação do trabalhador substituído; saber quem é; e principalmente a função que ele desempenhava, se vai substituir o empregado que está fora da empresa ou aquele que está cobrindo o que está fora. (art. 4 do RD 2720/98).

3. Se a substituição decorrer de um processo de seleção ou promoção para cobertura de uma vaga, o contrato deverá referir o posto de trabalho (art. 4 do RD 2564/94).

4. Sempre deve ser escrito, sob pena de ser considerado por "tempo indefinido", deve constar a modalidade contratual, a identificação da circunstância que determina sua duração e o trabalho a desenvolver. (art. 6 do RD 2720/98).

No Brasil, o contrato a prazo não possui uma formalidade essencial. Contudo, para garantia, principalmente do empregador, é recomendável sua forma escrita. Via de regra, a ausência de contrato escrito pode configurar um contrato por prazo determinado, como ocorre no contrato de safra (Lei 5.889/73).

Em outros casos de contratos por prazo determinado, a lei exige sua forma escrita. É o que ocorre, por exemplo, com o atleta profissional, artista e treinador de futebol.

O contrato temporário tem como seus principais requisitos:

a) O contrato escrito entre empregado e empregador (empresa intermediadora de mão de obra);

b) Contrato escrito (civil) entre a empresa prestadora e a tomadora, contendo o motivo da contratação;

c) Duração máxima de três meses, salvo autorização do Ministério do Trabalho, desde que não exceda seis meses ${ }^{20}$.

\section{DURAÇÃO DO CONTRATO}

No contrato de interinidad a duração, em princípio, será do tempo em que o trabalhador substituído estiver ausente (art. 4 do RD 2720/98). No caso da substituição para o processo de seleção ou promoção para cobertura de uma vaga a duração será a do processo de seleção ou de promoção, sem que ultrapasse três meses ${ }^{21}$.

Fica vedado celebrar um novo contrato com a mesma finalidade novamente depois de superado os três meses. Na administração pública o prazo é o estabelecido pela administração enquanto durar o processo seletivo.

As diversas leis que regulam a mais variadas formas de contrato por prazo determinado também estabelecem o seu prazo. De forma geral, a CLT fixa no art. 445 o prazo máximo de dois anos. $O$ contrato de trabalho do jogador de futebol é de prazo determinado, 
com prazo nunca inferior a três meses e não superior a cinco anos (art. 30 da Lei no 9.615/98). O contrato do treinador de futebol não pode ser estabelecido por mais de dois anos (art. 6, I, da Lei no 8.650/93).

Sendo o contrato de experiência o seu prazo não pode exceder noventa dias ( $§$ único da CLT).

Conforme já citado, no trabalho temporário, o contrato entre a empresa de trabalho temporário e a empresa tomadora de serviços, não poderá exceder o prazo de três meses, com relação a um mesmo empregado, salvo se autorizado pelo Ministério do Trabalho, poderá ser prorrogado uma única vez por igual período, desde que a empresa cliente justifique: a necessidade transitória de substituição de pessoal excedeu ao prazo inicialmente previsto; e as circunstâncias que geraram o acréscimo extraordinário dos serviços e ensejaram o contrato de trabalho foram mantidas. ${ }^{22}$

\section{JORNADA}

No contrato de interninidad, a regra geral é que o substituto cumpra a jornada completa, exceto em dois casos (art. 5.2. do RD 2720/98) (23: $^{2}$

a) quando o trabalhador substituído cumpria tempo parcial;

b) quando o contrato tenha como finalidade cumprir parte da jornada dos trabalhadores do tempo integral (com tempo reduzido) que por algum motivo não possam cumprir a jornada toda (nascimento de filhos prematuros hospitalizados, cuidado de um familiar até segundo grau de consangüinidade, por razões de idade, doença ou acidente e para cuidar de menores por doença ou câncer que implique numa internação duradoura.

De outra banda, no Brasil, tanto no contrato temporário como no contrato por prazo determinado, tendo em vista que não há uma substituição temporária de outro trabalhador que se ausenta por algum motivo, como na Espanha, a jornada depende da pactuação entre empregador e empregado ou, no caso do temporário, entre tomador e temporário.

\section{EXTINÇÃO DO CONTRATO}

Utilizando a mesma justificativa no caso da jornada, ou seja, levando em consideração que na realidade brasileira, o trabalhador temporário e o trabalhador contratado por prazo determinado, não substituem um posto de trabalho vacante provisoriamente pela ausência do trabalhador, findo o prazo de três meses, no caso do temporário, ou o prazo estipulado na lei, no caso do prazo determinado, está extinto de pleno direito o contrato.
Não há necessidade de comunicação prévia ou denuncia. Findo o prazo preestabelecido, as partes já sabem da extinção do contrato. Caso termine o prazo pactuado e a relação permaneça, com o prosseguimento das atividades, tem-se uma migração de modalidade. $\mathrm{O}$ desrespeito a algumas formalidades ou ao prazo máximo contratual conduz a alteração do contrato que passa a ser indeterminado, como no caso do contrato de experiência que excede os noventa dias ${ }^{24}$.

É importante destacar que um contrato a prazo determinado pode virar contrato a prazo indeterminado, mas o inverso é impossível ${ }^{25}$. Contudo, a não observância desses requisitos não gera vínculo com órgãos da administração pública ${ }^{26}$.

A seu turno, o contrato de interinidad, possui muito mais peculiaridades no que tange ao seu deadline. As formas de extinção do contrato de interinidad estão no art. 8.1.c), do Real Decreto 2720/9827.

Em primeiro lugar, a reincorporação do trabalhador substituído era uma causa de extinção do contrato, inclusive era a única modalidade até 1984. Outra possibilidade prevista é o vencimento do prazo legal ou convencional para reincorporação, situação bem próxima do nosso contrato por prazo determinado. A terceira possibilidade é a extinção da causa que originou a reserva do posto de trabalho - morte, incapacidade, aposentadoria e não reincorporação no tempo.

Essa modalidade merece uma análise mais cautelosa.

No caso da extinção por não reincorporação do substituído em tempo, é um contrato com condição que não se pode cumprir, devendo se conferir uma estabilidade jurídica e um contrato definitivo ${ }^{28}$.

Em seguida, um julgado do Tribunal Supremo definiu, em 1997, que além da reincorporação - única forma de extinção até ali aceita - também o contrato se extinguia quando desaparecia a reserva do posto de trabalho por razão de morte, aposentadoria, invalidez. No entanto, essa situação se modificou com o Real Decreto 2104/84, no art.4.2.d) que determinou que se considerava indefinido o contrato quando não ocorresse a reincorporação do trabalhador no prazo. Logo, essa situação também foi estendida para o caso de morte, invalidez e aposentadoria.

Todavia, o Real decreto 2546/1994 derrogou o 2104/84 e alterou novamente, com o acréscimo de outras situações, passando, então, a entender que a morte, aposentadoria e invalidez são causas extintivas, pois extinguem a causa que deu lugar a reserva do posto de trabalho.

$\mathrm{Na}$ verdade totalmente equivocado o entendimento, pois não se extingue o posto de trabalho, mas o substituído. Dessa forma é ilógica essa previsão 
espanhola. Nesse mesmo sentido a doutrina espanhola entende absurda essa interpretação, pois se cria uma expectativa para o interino de conservar seu trabalho na medida em que o substituído por algum motivo não pode ser reintegrado ${ }^{29}$.

Essa interpretação em verdade representa um completo retrocesso ${ }^{30}$.

Como última modalidade prevista, o transcurso do prazo para seleção ou promoção de empregado, também extingue o contrato de interinidad.

Por fim, destaca-se a ausência de indenização ao final do contrato que foi mantida em 2010. Cumpre destacar que o atualizado RD 20/2012 mantém a inexistência de qualquer bonificação ao término do contrato de interinidad ${ }^{31}$.

\section{REFERÊNCIAS}

BARREIRO GONZÁLEZ, G. Contratos para la sustitución de trabajadores con derecho a la reserva del puesto de trabajo. In: Contratos laborales temporales. Madrid: La Ley, 1993.
CASSAR, Vólia Bomfim. Direito do Trabalho. Niterói: Impetus, 2011.

DELGADO, Mauricio Godinho. Curso de Direito do Trabalho. São Paulo: LTr, 2011.

FERNÁNDEZ, Diego Megino. Algunas Reflexiones en Torno a la Prestación de Servicios en Régimen de Interinidad. Una Modalidad Contractual no Exenta de Controversia. In: DOMÍNGUEZ, Juan José Fernández; BARROSO, María de los Reyes Martínez; ESCANCIANO, Susana Rodríguez (Coord.). Derecho Del Trabajo - lecturas sobre la obra científica de Germán José María Barreiro González en sus XXV años como catedrático de Derecho del Trabajo. Curitiba: Juruá, 2012.

MARTINEZ, Luciano. Curso de Direito do Trabalho. São Paulo: Saraiva, 2012.

MARTINS, Sérgio Pinto. Direito do Trabalho. São Paulo: Atlas, 2010.

NASCIMENTO, Amauri Mascaro. Curso de Direito do Trabalho. São Paulo: Saraiva, 2010.

PEREIRA, Helena B. C. MICHAELIS: pequeno dicionário espanhol-português, português-espanhol. São Paulo: Companhia Melhoramentos, 1996.

PRIBERAM. Dicionário Priberam da língua portuguesa. Disponível em: <http://www.priberam.pt/dlpo/>. Acesso em: 07 dez. 12.

\section{NOTAS}

1 Dicionário Priberam da Língua Portuguesa. Disponível em: $<$ http://www. priberam.pt/dlpo/>. Acessado em: $07 \mathrm{dez} .12$ às 00:02.

2 PEREIRA, Helena B. C. MICHAELIS: pequeno dicionário espanholportuguês, português-espanhol. São Paulo: Companhia Melhoramentos, 1996, p. 170.

3 FERNÁNDEZ, Diego Megino. Op. cit., p. 132.

4 MARTINEZ, Luciano. Curso de direito do trabalho. São Paulo: Saraiva, 2012, p. 257.

5 Artículo 15. Duración del contrato.

1. El contrato de trabajo podrá concertarse por tiempo indefinido o por una duración determinada. Podrán celebrarse contratos de duración determinada en los siguientes supuestos:

(...)

c) cuando se trate de sustituir a trabajadores con derecho a reserva del puesto de trabajo, siempre que en el contrato de trabajo se especifique el nombre del sustituido y la causa de sustitución.

6 Artículo 4. Contrato de interinidad.

1. El contrato de interinidad es el celebrado para sustituir a un trabajador de la empresa con derecho a la reserva del puesto de trabajo en virtud de norma, convenio colectivo o acuerdo individual.

El contrato de interinidad se podrá celebrar, asimismo, para cubrir temporalmente un puesto de trabajo durante el proceso de selección o promoción para su cobertura definitiva.

7 FERNÁNDEZ, Diego Megino. Algunas reflexiones en torno a la prestación de servicios en régimen de interinidad. Una modalidad contractual no exenta de controversia. In: Derecho Del Trabajo - Lecturas sobre la obra científica de Germán José María Barreiro González en sus XXV años como catedrático de Derecho del Trabajo. Coord. Juan José Fernández Domínguez, María de los Reyes Martínez Barroso, Susana Rodríguez Escanciano. Curitiba: Juruá, 2012. p. 133

8 Disponível em: <http://www.empleo.gob.es/es/guia/texto/guia_4/ contenidos/guia 4 11 13.htm>. Acessada em: 19 out. 2012 às 20:54.

9 NASCIMENTO, Amauri Mascaro. Curso de Direito do Trabalho. São Paulo: Saraiva, 2010. p. 1004.

${ }^{10}$ DELGADO, Maurício Godinho. Curso de Direito do Trabalho. São Paulo: LTr, 2011, p. 447

${ }^{11}$ MARTINS, Sérgio Pinto. Direito do Trabalho. São Paulo: Atlas, 2010. p. 111; tb. nesse sentido DELGADO, Maurício Godinho, op. cit., p. 515

${ }_{12}$ CASSAR, Vólia Bomfim. Direito do Trabalho. Niterói: Impetus, 2011. p. 642 .
${ }^{13}$ MARTINS, Sérgio Pinto. op. cit. p. 156.

${ }^{14}$ DELGADO, Maurício Godinho, op. cit. p. 447.

${ }^{15}$ Contrato Temporário. Preenchimento de Vaga de Empregado Afastado Temporariamente. Previsão em Edital de Concurso Público.

Ementa:

CONTRATO TEMPORÁRIO. PREENCHIMENTO DE VAGA DE EMPREGADO AFASTADO TEMPORARIAMENTE. PREVISÃO EM EDITAL DE CONCURSO PÚBLICO.

É regular a contratação temporária de candidato aprovado em concurso público, para substituição de empregado afastado por prazo determinado, quando houver previsão nesse sentido em edital que regulamenta o processo seletivo público e for atendido o disposto no art. 443, $\leqslant 2^{\circ}$. da CLT. (TRT-4 - RECURSO ORDINARIO TRABALHISTA: RO 721008120095040007 RS 0072100-81.2009.5.04.0007)

${ }^{16}$ Ibidem. p. 516

17 MARTINEZ, Luciano. op. cit. p. 244.

${ }^{18}$ El contrato de interinidad tendrá el siguiente régimen jurídico:

El contrato deberá identificar al trabajador sustituido y la causa de la sustitución, indicando si el puesto de trabajo a desempeñar será el del trabajador sustituido o el de otro trabajador de la empresa que pase a desempeñar el puesto de aquél.

En el supuesto previsto en el segundo párrafo del apartado 1, el contrato deberá identificar el puesto de trabajo cuya cobertura definitiva se producirá tras el proceso de selección externa o promoción interna. La duración del contrato de interinidad será la del tiempo que dure la ausencia del trabajador sustituido con derecho a la reserva del puesto de trabajo.

En el supuesto previsto en el segundo párrafo del apartado 1, la duración será la del tiempo que dure el proceso de selección o promoción para la cobertura definitiva del puesto, sin que pueda ser superior a tres meses, ni celebrarse un nuevo contrato con el mismo objeto una vez superada dicha duración máxima.

En los procesos de selección llevados a cabo por las Administraciones públicas para la provisión de puestos de trabajo, la duración de los contratos coincidirá con el tiempo que duren dichos procesos conforme a lo previsto en su normativa específica.

19 FERNÁNDEZ, Diego Megino. op. cit., p. 135

${ }^{20}$ CASSAR, Vólia Bomfim, op. cit., p. 320.

${ }^{21}$ Contudo, o próprio RD 2720/98, define nas causas de extinção do referido contrato, em seu art. 8.1.c), outras modalidades: La reincorporación del trabajador sustituido (quando não há prazo previamente definido), El vencimiento del plazo legal o convencionalmente establecido para 
la reincorporación (caso de conhecimento do prazo (cumprimento do serviço militar); La extinción de la causa que dio lugar a la reserva del puesto de trabajo (representação sindicial); El transcurso del plazo de tres meses en los procesos de selección o promoción para la provisión definitiva de puestos de trabajo o del plazo que resulte de aplicación en los procesos de selección en las Administraciones públicas.

22 MARTINEZ, Luciano. op. cit., p. 261.

${ }^{23}$ El contrato de interinidad deberá celebrarse a jornada completa excepto en los dos supuestos siguientes:

Cuando el trabajador sustituido estuviera contratado a tiempo parcial o se trate de cubrir temporalmente un puesto de trabajo cuya cobertura definitiva se vaya a realizar a tiempo parcial.

Cuando el contrato se realice para complementar la jornada reducida de los trabajadores que ejerciten los derechos reconocidos en el artículo 37, apartados 4. bis y 5 del Estatuto de los Trabajadores, o en aquellos otros casos en que, de conformidad con lo establecido legal o convencionalmente, se haya acordado una reducción temporal de la jornada del trabajador sustituido, incluidos los supuestos en que los trabajadores disfruten a tiempo parcial del permiso de maternidad, adopción o acogimiento, preadoptivo o permanente, de acuerdo con lo establecido en el párrafo sexto del apartado 4 del artículo 48 del Estatuto de los Trabajadores.

${ }^{24}$ Nesse sentido DELGADO, Maurício Godinho, op. cit., p. 521; e MARTINEZ, Luciano. op. cit., p. 264.

25 NASCIMENTO, Amauri Mascaro. op. cit,. p. 983.

26 RECURSO DE REVISTA. TERCEIRIZAÇÃO. APPA. ISONOMIA SALARIAL. APLICAÇÃO ANALÓGICA DA LEI No 6.019/74. A jurisprudência desta Corte é pacífica no sentido de que a contratação irregular não gera vínculo com os órgãos da administração pública, direta ou indireta (Súmula 331, II, do TST). Contudo, a impossibilidade de se formar vínculo com a administração pública não afasta o direito do trabalhador terceirizado às mesmas verbas asseguradas aos empregados públicos que exerçam funções idênticas àquele. Com efeito, o Direito do Trabalho caracteriza-se pela presença de mecanismos e princípios que intentam evitar tratamentos discriminatórios entre obreiros que se encontrem na execução de tarefas iguais e submetidos a idênticos encargos, por ocasião da prestação de serviço. A Constituição Federal, em seus artigos $5^{\circ}$, caput, e $7^{\circ}$, XXXII e XXXIV, consagra o princípio da isonomia e afugenta o tratamento discriminatório. O princípio da isonomia visa, também, a evitar tratamento salarial diferenciado àqueles trabalhadores que exerçam trabalho igual para um mesmo empregador. A equiparação salarial encontra fundamento jurídico na própria Carta (artigos $5^{\circ}$, caput, e $7^{\circ}$, XXXII e XXXIV), bem como em normas esparsas, como a do artigo 12 da Lei 6.019/74. Ao estabelecer preceito de isonomia remuneratória, esta norma concretiza os dispositivos constitucionais concernentes à ideia de isonomia e proteção ao salário (art. 7ํ, VI, VII e X, da Constituição Federal). Daí por que, embora não tenha sido a Reclamante contratada com base na Lei 6.019/74, o preceito que assegura o salário equitativo impõe-se a quaisquer outras situações de terceirização. Aplicável, portanto, o artigo 12, "a", da Lei 6.019/74, de forma analógica, ao contrato de trabalho do Reclamante. Recurso de revista parcialmente conhecido e provido. (RR - 4370018.2002.5.09.0022, Relator Ministro: Horácio Raymundo de Senna Pires, Data de julgamento: 28/04/2010, 3aㅡ Turma, Data de publicação: 14/05/2010).

27 Artículo 8. Extinción y denuncia de los contratos.

Los contratos de duración determinada se extinguirán, previa denuncia de cualquiera de las partes, por las siguientes causas:

1. El contrato de interinidad se extinguirá cuando se produzca cualquiera de las siguientes causas:

2. La reincorporación del trabajador sustituido.

3. El vencimiento del plazo legal o convencionalmente establecido para la reincorporación.

4. La extinción de la causa que dio lugar a la reserva del puesto de trabajo. 5. El transcurso del plazo de tres meses en los procesos de selección o promoción para la provisión definitiva de puestos de trabajo o del plazo que resulte de aplicación en los procesos de selección en las Administraciones públicas.

28 BARREIRO GONZÁLEZ, G. Contratos para la sustitución de trabajadores con derecho a la reserva del puesto de trabajo. in: Contratos laborales temporales. Madrid: La Ley, 1993, p. 135.

${ }^{29}$ Ibidem, p. 113.

30 FERNÁNDEZ, Diego Megino. op. cit., p. 146.

${ }^{31}$ Disposición transitoria sexta. Supresión del derecho a la aplicación de bonificaciones.

1. a) Queda suprimido el derecho de las empresas a la aplicación de bonificaciones por contratación, mantenimiento del empleo o fomento del autoempleo, en las cuotas a la Seguridad Social y, en su caso, cuotas de recaudación conjunta, que se estén aplicando a la entrada en vigor de este Real Decreto-ley, en virtud de cualquier norma, en vigor o derogada, en que hubieran sido establecidas.

b) Lo dispuesto en el párrafo anterior será de aplicación a las bonificaciones en las cuotas devengadas a partir del mes siguiente al de la entrada en vigor de este Real Decreto-ley.

2. No será de aplicación lo previsto en el apartado 1 a las bonificaciones recogidas en las siguientes disposiciones:

(...)

f) Real Decreto-ley $11 / 98$, de 4 de septiembre, por el que se regulan las bonificaciones de cuotas a la Seguridad Social de los contratos de interinidad que se celebren con personas desempleadas para sustituir a trabajadores durante los períodos de descanso por maternidad, adopción $\mathrm{y}$ acogimiento. 